\title{
Preface
}

In 1950, the East Asiatic Library of the University of California acquired by purchase from Japan a large private library of printed books, manuscripts, maps, and rubbings. This important acquisition at once raised the research facilities in the Far Eastern field at Berkeley to the level, in quality as well as quantity, of the famous older collections elsewhere in the United States. Korean studies were especially enriched by the part of the acquisition called the Asami collection, which comprises over nine hundred titles of Korean printed books, manuscripts, and rubbings in about four thousand fascicles and sheets, approximately one third of which are documents relating to law and government. At present, the Asami collection is the largest of its kind in this country. (Other notable collections are the Frederick McCormick collection at the Honnold Library at Claremont College, the Rockhill collection at the Library of Congress, and the Yale collection assembled by Asakawa.)

About sixty examples of movable-type printing from the seventeenth to nineteenth centuries appear in the Asami collection. Although this selection is not comparable to the examples of pre-1592 movable-type printing in some Japanese government libraries and in several private collections in Korea, it is neverthless unique. Until relatively recent times, Korean movable-type editions were limited to three or four hundred copies at most. But these books are not only rare: some of them are examples of a highly specialized printing art.

Asami Rintarō (1869-1943), the Japanese scholar who assembled the collection, was a graduate of the Department of Law of Tokyo Imperial University. He served as a legal adviser and then as a judge in 
Seoul from July 1906 to March 1918, and later practiced law in Fujisawa, Japan. While in Seoul he joined a group of Japanese bibliophiles who made a hobby of collecting Korean books. Asami probably began his collection with books relating to law and government, and only later added works in other fields. He served on the advisory board of the publishing society Chōsen Kosho Kankōkai, and was writing introductions to some of its publications at the time when McCormick was also actively collecting Korean books - shortly after the publication of Maurice Courant's Bibliographie coréenne (Paris, 1902-1910, 3 vols.), and the assembling of Rockhill's collection. Among Asami's associates in collecting Korean books were Maema Kyōsaku (1868-1942) and Imanishi Ryū (1875-1932), who were also connected with the Chōsen Kosho Kankōkai. The Imanishi collection is now in the Tenri Library, and the Maema collection in the Tōyō Bunko. Judging from the catalogues of those two collections, they seem comparable in quantity to the Asami collection.

The Asami collection is the only one of the three whose contents have never been itemized in detail. Only two partial lists have been made. One is in the bibliography to Asami's doctoral thesis, Chösen hösei shi kō (Tokyo, 1922), where about a third of the titles found in our collection are listed. Another list is that quoted as Asami shüsho soken by Maema in his comprehensive bibliography of Korean books, Kosen sappu. For a time Maema and Asami lived not far apart in Seoul, and about 1910 they often exchanged duplicates or lent each other items for collation. But the list of Asami's books consulted by Maema seems to have been an early one, for it does not include many important items evidently acquired in later years.

Before opening the Asami collection to readers, Dr. Elizabeth Huff, director of the East Asiatic Library, thought it desirable to have a descriptive catalogue prepared, and in 1955 I was engaged for that purpose. But in 1957, after a preliminary survey had been made, the work was interrupted. In 1960 I made a short visit to Korea and Japan to consult some of the bibliophiles engaged in Korean studies, especially about the history of Korean movable-type printing.

During the compilation of this work, I have attempted to follow certain standard practices in matters of style. I have used the McCuneReischauer system of romanization,* and the Library of Congress rules on word division. The classification scheme is that of the revised edition

\footnotetext{
* The word mun'gwa is spelled mungwa throughout this book. Since the meaning of the word is completely unambiguous, the present spelling reflects expedience rather than precedent.
} 
of Chösen tosho kaidai. Several reference works have been consulted constantly, and thus are cited only in cases of discrepancies in facts or figures. Among them are: Chōsen tosho kaidai (referred to as Kaidai); Kosen sappu (referred to as Maema); Chösen jimmei jisho; and Chösen shi. References to Richō jitsuroku (referred to by the original Korean title of the sillok of each reign) and to Mansong taedongbo (referred to as Taedongbo) are usually given with either page or kwŏn and leaf numbers to facilitate their location.

Whatever the defects of this catalogue, they are due to my own deficiencies and not to the generous assistance that $I$ have received in the course of its preparation. Professor Yi Pyong-do read parts of the manuscript in 1957 and made valuable suggestions and corrections, as did Professor Yang Lien-sheng in the same year. Aid in typing, romanization, and other tedious tasks was rendered by Powkey Sohn, Paek Hur, Mrs. Changsoo Swanson, George Yü, and Ellen M. Gumperz, who also gave editorial assistance. The calligraphy reproduced throughout the text is in the hand of Mrs. Yoshimi K. Nakamura. Valuable information about the history of movable-type printing in Korea was furnished first by Powkey Sohn and later by Kim Doo-jong, Kim Won-yong, Fukui Tamotsu, Tagawa Kozo, Chiang Fu-ts'ung, and Ch'ang Pi-te. During my 1960 visit to the Far East, useful information on various matters Korean was also received from Professors Yi Pyong-do, Yi Sang-un, Suematsu Yasukazu, and Imanishi Shunjū. I am also grateful for the help in preparing this manuscript given by my wife, Lienche $\mathrm{Tu}$, and by Dr. Richard G. Irwin, Mrs. Ch'ung-ho Frankel, Charles E. Hamilton, and other colleagues in the East Asiatic Library.

\section{CHAOYING FANG}

Berkeley, 1961

\section{POSTSCRIPT}

After writing the above, I stayed two years in Canberra as associate librarian in the Australian National University and in 1963 came back to New York to work in the Ming Biographical History Project. Four years later, during the summer of 1967, at the generous invitation of the University of California, I returned to the East Asiatic Library to help in editing the catalogue for publication. The main difference from the original version is the addition of short descriptions of the rubbings, which were written with the assistance of John Jamieson and his wife, Chol-hee. It was I who benefited most from editing the manuscript and 
reading it again, and renewing my acquaintance with the excellent collection of Korean books in the East Asiatic Library, those in the main stack as well as in the Asami collection.

When I read again the Sŏlmun haeja ikching by Pak Sŏn-su, I was even more impressed than at first by his theory that the character read as erh ('two') in some ancient Chinese texts was probably a mistake for the character written similarly but read shang ('up', 'top', 'above'). I extended this discovery to the interpretation of the character jen, representing the main tenet of the teaching of Confucius, and came to the conclusion that the character was not formed from the characters for 'man' and 'two' but from 'man' and 'above', indicating that the original meaning was the person above, the master, or the sovereign. I offer this as a new interpretation of the character after some two thousand years. For this discovery I feel greatly indebted to Pak and to the opportunity to examine again the Korean books in Berkeley.

I should like to express my gratitude to all of my friends in Berkeley who extended their hospitality to me during the summer of 1967, particularly to Elizabeth Huff, Richard G. Irwin, Charles E. Hamilton, other former colleagues in the East Asiatic Library, and to Yong Kyu Choo, Michael C. Rogers, and Shih-hsiang Chen. I wish especially to express my gratitude to Dr. Elizabeth Huff for her encouragement in this work and for the final editing of the manuscript. All responsibility for statements of fact and opinion rests, of course, with me. 